\title{
The Effects of Wealth and Income on Subjective Well-Being and Ill-Being*
}

\author{
Bruce Headey and Mark Wooden \\ Melbourne Institute of Applied Economic and Social Research \\ The University of Melbourne
}

Melbourne Institute Working Paper No. 3/04

ISSN 1328-4991 (Print)

ISSN 1447-5863 (Online)

ISBN 0734031459

March 2004

* This paper reports on research being conducted as part of the research program, "The Dynamics of Economic and Social Change: An Analysis of the Household, Income and Labour Dynamics in Australia Survey". It is supported by an Australian Research Council Discovery Grant (DP0342970). The paper uses the data in the confidentialised unit record file from the Department of Family and Community Services' (FaCS) Household, Income and Labour Dynamics in Australia Survey, which is managed by the Melbourne Institute of Applied Economic and Social Research. The findings and views reported in the paper, however, are those of the authors and should not be attributed to either FaCS or the Melbourne Institute. The authors are also grateful to John Creedy for helpful comments.

Melbourne Institute of Applied Economic and Social Research

The University of Melbourne

Victoria 3010 Australia

Telephone (03) 83445330

Fax (03) 83445630

Email melb-inst@unimelb.edu.au

WWW Address http://www.melbourneinstitute.com 


\begin{abstract}
The accepted view among psychologists and, increasingly, economists is that household income has statistically significant but only small effects on measures of subjective wellbeing. Income, however, is clearly an imperfect measure of the economic circumstances of households. Using data drawn from the 2002 wave of the Household, Income and Labour Dynamics in Australia (HILDA) Survey, this paper demonstrates that wealth, which can be viewed as providing a degree of economic security, is at least as important to well-being and ill-being as income.
\end{abstract}




\section{Introduction}

A conventional assumption in most microeconomic text books is that money can buy happiness. The accepted view in psychology, however, is that the objective economic circumstances have only a slight though statistically significant effect on happiness and other measures of well-being (Andrews and Withey 1976; Argyle 1987; Campbell, Converse and Rodgers 1976; Diener and Biswas-Diener 2002; Diener et al. 1999; Headey and Wearing 1992; Kahnemann, Diener and Schwarz 1999). This view seems also to now be supported by a growing body of empirical work by economists. Beginning with the seminal work of Easterlin (1974), an increasing number of economists have analysed the association between income and subjective measures of well-being and have concluded that the positive effects of extra income on quality of life are relatively small (e.g., Oswald 1997; Frey and Stutzer 2000; Clark 2003; Blanchflower and Oswald 2004). ${ }^{1}$ However, the claim that money has little effect on happiness is almost entirely based on weak relationships between survey measures of happiness and measures of income. The single exception appears to be a paper by Mullis (1992), which was based on a sample of American men aged between 55 and 69 years of age, and showed that, for this group, income and wealth combined additively to affect scores on a composite index of satisfaction with standard of living, housing, neighbourhood, health, leisure and 'life in general'.

In this paper we test the hypothesis that it is wealth rather than income that matters most for well-being using data covering a wide population. Specifically, data from the new Household, Income and Labour Dynamics in Australia (HILDA) Survey are used to estimate the combined effects of disposable income and wealth (net worth) on measures of subjective

\footnotetext{
1 There are, however, some notable exceptions which find quite large impacts (e.g., Frijters, Haisken-DeNew
} and Shields forthcoming). 
well-being (SWB) and ill-being. The analysis indicates that objective economic circumstances have a greater impact on subjective outcomes than suggested by most previous empirical studies.

We stress that this paper assesses the impact of economic circumstances on ill-being (or psychological distress) as well as well-being (or happiness). So far as we know, it is the first paper which imports into economics a key result from the psychological literature namely that well-being and ill-being are distinct dimensions and not opposite ends of the same dimension (Bradburn 1969; Diener 1984; Diener et al. 1999; Headey Kelley and Wearing 1993; Headey and Wearing 1992). The issue here is whether objective economic circumstances do more to promote well-being or relieve ill-being, or have about the same impact on both. Our results provide most support for the latter hypothesis.

\section{Economic and Psychological Theory}

For most of the $20^{\text {th }}$ century, the two major social science literatures on happiness and well-being - the economic literature on utility and the psychological literature on SWB steadfastly ignored each other. ${ }^{2}$ Welfare economists learn not to measure utility directly, but instead to infer it from behaviour. Following Samuelson (1938), the standard approach is to treat behaviours as 'revealed preferences'. Utility is viewed as involving trade-offs between work and leisure. Work is regarded as pain but provides the wherewithal for consumption, while leisure is regarded as pleasure. Individuals are viewed as making different trade-offs,

\footnotetext{
2 In contrast, much of the early work on utility by economists of the $19^{\text {th }}$ century, notably Francis Edgeworth and William Stanley Jevons, was much informed by the work of the major figures in experimental psychology of their day (see Creedy 1986, pp. 28-29).
} 
depending on their preferences for consumption and leisure, but essentially a happy person is seen as someone with a full shopping basket and lots of free time; a rather hedonistic view.

In psychology, empirical research on well-being and happiness began in the late 1960s and 1970s at the Universities of Chicago (Bradburn 1969 and Michigan (Andrews and Withey 1976; Campbell, Converse and Rodgers 1976). The early studies made two discoveries that are still debated but are accepted by the large majority of researchers. These discoveries, if correct, are of great importance to economists.

First, well-being (or happiness) and ill-being (or psychological distress) are empirically distinct dimensions with different causes; they are not opposite ends of the same dimension. Well-being comprises life satisfaction and positive feelings (e.g., joy, vitality), or what psychologists call positive affects. Ill-being comprises anxiety, depression and other negative affects. There is much evidence that people can experience both high levels of wellbeing and also quite high levels of anxiety at the same time (see Headey, Kelley and Wearing 1993).

Second, economic variables, notably income, appear to have little effect on either well-being or ill-being. This is part of a more general finding that objective circumstances of all kinds (such as gender, age and employment status) have only modest effects on subjective outcomes. Well-being turns out to be much more affected by personality traits, personal relationships and social participation, and ill-being by personality problems, marital problems, job problems (including unemployment) and self-assessed health.

In recent years, economists have begun to take an interest in the psychological literature (see Frey and Stutzer 2002 for a review). An important motivation for the recent interest among economists in psychological theories and results relating to well-being is a concern that the 'revealed preferences' approach may be open to challenge. This approach 
depends on the assumption that people's preferences for goods and leisure are exogenously determined and hence that increases in supply will increase utility. However, if people change their preferences in response to what others have and want, as proposed by Duesenberry (1949), then one cannot reasonably infer that more goods and leisure, preferred at time $t$, will necessarily increase utility if acquired at time $t+1$. Easterlin (1974) provided support for Duesenberry's theory by showing that, in so far as income affects happiness at all, it is relative income - one's income relative to others in one's own country - and not absolute gains in income that make a difference. A recent issue of the Journal of Economic Behavior and Organization (July, 2001; see especially Hollaender, pp. 227-49) was devoted to the debate about whether preferences are exogenous or endogenous, and the major implications for welfare economics of accepting the latter standpoint (see also Frank 1985).

Some economists might concede that, while it might be desirable to measure utility directly, it cannot be done in a reasonably valid way. Economists have been trained to the view that it is impossible to make interpersonal comparisons of utility. Can anyone really believe, they ask, that a person who scores 80 on a survey measure of satisfaction is more satisfied than someone who scores 70 or 75 ? Psychologists who have developed measures of well-being might reply that, taken literally, no-one does believe that. But, they might also reply, do economists literally believe that someone who reports an income of $\$ 80,000$ in a survey or a tax return really has a higher income than someone who reports $\$ 70,000$ or $\$ 75,000$ ? What the psychologists claim is that, in general, the people who score higher on satisfaction scales are more satisfied than people who score lower, and 'in general' is all that is needed for statistical analysis or, one might add, for business and government decisionmaking. 
A limitation of the recent work in economics is a lack of recognition that well-being is probably better regarded as multi-dimensional, not unidimensional. To date those economists who have reported results involving direct measurement of well-being have usually conceptualized it as 'satisfaction'; either life satisfaction or satisfaction with one's material standard of living or financial situation. So far as we know, no previous research has investigated the impact of economic circumstances on ill-being, as well as well-being.

\section{Data and Methods}

\section{(i) The HILDA Survey}

The data for this analysis come from the second wave of the HILDA Survey, conducted in 2002. Described in more detail in Watson and Wooden (2002), the HILDA Survey is a household panel survey. It began with a large national probability sample of households, and involved personal interviews with all household members aged 15 years and over. In wave 1, conducted during the second half of 2001, interviews were obtained at 7682 households, which represent 66 per cent of all households identified as in-scope. This, in turn generated, a sample of 15,127 persons eligible for interview, 13,969 of whom were successfully interviewed.

A year later all responding households from wave 1 were re-contacted. Interviews were again sought with all household members aged 15 years or over, including persons who did not respond in wave 1 , as well as any new household members. In total, interviews were completed with 13,041 persons from 7245 households. Of this group almost 12,000 were respondents from wave 1 , which represents almost 87 per cent of the wave 1 individual sample. 
The coverage of the survey is extremely broad, but with a focus on household structure and formation, income and economic well-being, and employment and labour force participation. Each year a special module of non-core questions is added. In wave 1 it was appropriate to devote the module to personal and family history. In wave 2 the topic was wealth. Each year's survey also includes a leave-behind self-completion questionnaire, which mainly contains attitude questions. Among the topics covered are experiences of financial stress and deprivation, social networks, attitudes to saving and borrowing, and physical and psychological health.

For this paper we restrict the sample to persons of prime working age (25-59 years) at 30 June 2002, reducing the final sample to 7934 observations. This exclusion seems justified on the grounds that the economic concerns of younger people and retirees tend to be quite different from the prime age group. Younger people typically do not expect to earn much many are still in education - and retirees, being mostly not in paid work, care primarily about their superannuation assets and pension income.

Cross-sectional weights have been used in reporting means and standard deviations, and for making 'predictions' about the impact of economic circumstances on SWB. As is usual, weights were not used in regression analyses.

\section{(ii) Well-being Measures}

Two indicators of subjective well-being were used and two of ill-being. The wellbeing indicators were single item measures of 'overall life satisfaction' and 'satisfaction with your financial situation'. The ill-being measures were a 5-item scale based on the mental health sub-scale included in the SF-36 Health Survey and a measure of 'financial stress' constructed from eight questions about difficulty in paying bills and dealing with financial emergencies (see below). It should be noted that, both for well-being and ill-being, one 
measure relates to the concept defined very broadly and one relates specifically to the economic/financial domain of life.

The concept of life satisfaction is perhaps closest to what welfare economists say they mean by utility, and is the concept employed in nearly all the recent studies by economists who have chosen to measure utility directly. On the other hand, satisfaction / dissatisfaction with one's financial situation, or satisfaction / dissatisfaction with material standards of living, seem to be the outcomes most likely to result from the variables that are actually included in most welfare economics equations and from the variables measuring family economic circumstances, which are our focus here.

Life satisfaction and financial satisfaction were both measured by single questions scored on a $0-10$ scale. Only the extreme values were labelled, with a score of 0 described as 'totally dissatisfied' and a score of 10 as 'totally satisfied'. For ease of interpretation these scales - and the ill-being measures also - were rescored to run from 0 to 100 . This means that the coefficients in regression results can be understood as showing the quasi-percentage increases or decreases in well-being or ill-being that would result from one unit of change in the explanatory variable in question (net of the effects of other variables on the right hand side).

Clearly, single item scales are not the best measures of well-being available, but they are very widely used in international surveys and have been found to have acceptable levels of reliability and validity (Diener et al. 1999, pp. 277-278). It appears that, in relation to life satisfaction in particular, human beings can make quick global judgments in survey interviews; judgments which pretty accurately summarize their feelings. The global judgments that individuals make about themselves are corroborated by external validity tests done with partners and friends (Diener et al. 1999). Judgments of life satisfaction prove to be 
reasonably stable; they have a test-retest reliability of around 0.6 , which is about the same as standard tests of blood pressure.

The broad measure of ill-being included here - the SF-36 mental health scale - is based on questions about a spectrum of negative feelings, such as anxiety, depression, and tension. Our domain specific measure of financial ill-being combined and gave equal weights to eight questions about the inability to pay bills, need to pawn possessions, going without meals, going without heating, needing help from friends, family or welfare organizations, and difficulty in raising \$2000 to meet an emergency.

\section{(iii) Wealth and Income}

Not much is known about household wealth in Australia. The Reserve Bank publishes a household balance sheet each year, but the numbers are derived from the National Accounts and other aggregate sources and are, to a considerable extent, residuals calculated after business assets (about which much is known) have been accounted for.

The wealth module included in Wave 2 of the HILDA Survey represents the first survey-based attempt in Australia for several decades to measure wealth at the household level. Most of the questions about assets and debts were in fact asked at the household level and answered by one person on behalf of the entire household. The questions covered housing, incorporated and unincorporated businesses, equity-type investments (e.g., shares, managed funds) and cash-type investments (e.g., bonds, debentures), vehicles and collectibles (e.g., art works). However, some questions about assets and debts - those that could not be reported accurately by one person on behalf of all - were asked of individuals. These included superannuation, bank accounts, credit card debt, HECS debt and other personal debt. In answering all questions, respondents were asked to give exact dollar amounts. However, 
bands were offered to those who could not provide a more exact estimate of their superannuation holdings; a particularly difficult topic.

Wealth is difficult to measure in surveys and, when it has been attempted overseas, has been associated with high item non-response rates and under-estimates of national wealth of typically about 25 per cent, if the National Accounts are taken as a benchmark (Juster, Smith and Stafford 1999). This last result is partly due to under-reporting and partly because the wealthiest two per cent or so, who own a vastly disproportionate share, are invariably under-represented in surveys. Furthermore, an equal probability sample will always be poorly placed to measure wealth, given that wealth is so concentrated at one end of the distribution.

The HILDA Survey was clearly not immune to these difficulties. For example, despite item response rates on most wealth components of over 90 per cent, we were only able to directly compute net household wealth for 64.4 per cent of all households responding in Wave 2. ${ }^{3}$ To avoid the likely bias from dropping all cases with missing data, the wealth measure used in this analysis replaces all missing values on the major wealth components with imputed values. ${ }^{4}$ The imputation process was undertaken by staff of the Reserve Bank of Australia, and involved estimating regression models for each of the major components of wealth. The results from these regressions were then used to identify a 'nearest neighbour' from the sample of households with complete data for the relevant wealth component. The responses of these 'neighbours' were then used to fill in for the missing values.

Comparison with the Reserve Bank's national aggregates suggests that HILDA's household wealth estimates after imputation seem reasonable, with the HILDA Survey

3 Part of the problem here is that only at 90 per cent of responding households are interviews completed with all members of the household.

4 The variable is included as part of the public Wave 2 data release. 
appears to have under-estimated net worth by only around 10 per cent (see Headey, Marks and Wooden forthcoming). This is likely to be almost entirely due to inadequate representation of the very wealthy. Our wealthiest household, for example, had a reported net worth of $\$ 22$ million, which is well below the levels recorded for individuals listed in the BRW list of Australia's 200 wealthiest people.

Note that the variable we use to measure wealth is net worth at the household level. In other words, even where questions were asked at the individual level, we have summed the results for all household members and attributed the same net worth to each person.

Turning now to income, individual respondents are asked each wave to provide extensive details about their income from all sources during the preceding financial year. That includes labour income (wages and salaries), asset income (business income, rental income, share dividends, etc.), private superannuation income, private transfers (e.g., child support payments) and public transfers (pensions, benefits). Like all other surveys, HILDA does not ask about taxes, since most people could not answer accurately. So in order to estimate disposable incomes, taxes have to be imputed. Again, there is a problem with missing data, with the necessary data to construct household income missing in almost 28 per cent of cases in wave 2. So we again used the household income variable provided in the data file that includes imputed estimates for missing cases.

The main measure of income used in this paper is household disposable income, which, with some adjustment (discussed below), is widely regarded as the best income-based measure of material standard of living. As with wealth, our measure is based on summing the incomes of all household members and implicitly assuming that resources are shared.

Obviously a small household with the same income as a large household would have a higher standard of living, so it is necessary to make some adjustment for household size. We 
cannot, however, simply divide household income by the number of household members since this makes no allowance for economies of scale in larger households or for the fact that children are cheaper to keep than adults. The usual way to make the adjustment is to use an equivalence scale; a scale intended to assist measurement of standard of living by adjusting household income to needs. In this paper the equivalence scale we use is the so-called International Experts' Scale, which represents a compromise among the wide range of scales explicitly or implicitly used by Western governments in running their social assistance programs (Buhmann et al. 1988). Use of the scale requires dividing household disposable income by the square root of household size. So a four-person household with a disposable income of $\$ 40,000$ is deemed to have an equivalent income of $\$ 20,000 .{ }^{5}$ Note that we did not equivalise wealth (net worth) because, for reasons unclear, equivalised wealth correlated with dependent variables much less strongly than the unequivalised variable.

A further measurement issue was whether to use logarithmic transformations of wealth and income in regression equations. Economists normally prefer to take logs of income-like measures because the distributions are usually lognormal rather than normal, due to small numbers of very rich people (in the right tail of the distribution). Inspection of the data for wealth indicated the necessity of a log transformation. However, equivalised disposable income has a distribution which is very close to normal, so a log transformation is not a statistical necessity. Empirically in Australia, and in other countries, equivalised income correlates a little more highly with measures of well-being and ill-being than the $\log$ of equivalised income. So on empirical grounds we did not take logs.

5 Results are very close to those obtained for the current OECD scale of 1.0 for the first adult in a household, 0.5 for other adults and 0.3 for children. 
IV Results

(i) Well-being

By international standards, Australians score high on well-being, with a mean score for this age group of 77.0 on the $0-100$ scale. We also find that women are slightly more likely to report higher levels of life satisfaction than men (mean $=77.5$ compared with 76.5 for men), a result different from most other Western countries, but one that is found in all Australian studies that we have seen.

The Pearson correlations between measures of household economic circumstances and well-being give a first clue to the fact that we are going to find stronger relationships than in previous research. The simple correlations between equivalised disposable income and life satisfaction, and between income and financial satisfaction, are 0.11 and 0.27 respectively, very similar to what has been reported in previous research. However, the correlations with wealth are actually higher than for income; 0.15 for life satisfaction and 0.33 for financial satisfaction.

We now assess the combined effects of wealth and income, and also control for a small number of other 'objective' characteristics of respondents; sex, age, marital status, educational attainment, employment status and disability status. ${ }^{6}$ Ordinary least squares (OLS) regression was used, although it is recognized that, strictly speaking, three of the dependent variables are only ordinal. However, ordered probit equations gave results that

6 The construction of most of these control variables is straightforward and should require little by way of explanation. The exception here is disability status. Respondents were classified as disabled if they had any long-term health condition, impairment or disability that restricted their everyday activities and had lasted, or was likely to last, for 6 months more. Following Shields and Wooden (2003), we then further decomposed this group into three sub-groups according to the severity of the disability based on how much the disability limited the type or amount of work thy could undertake. Those who could do no work at all were classified as severely disabled. Those whose disability had no impact on their ability to work were classified as mildly disabled. All other disabled persons were classified as having a moderate disability. 
were qualitatively the same, so like most previous researchers in the field of SWB, we preferred to give the more readily interpretable OLS results. ${ }^{7}$ Note that, given the evidence of heteroscedasticity, all equations have been estimated with robust standard errors.

Using the evidence in Table 1 to reconsider the effects of objective economic circumstances on well-being, one is faced with the standard worry about whether to see the bottle as half empty or half full. Clearly the inclusion of wealth helps to account for more variance than just income by itself. One slightly crude way to compare the relative importance of wealth and income to well-being is to compare the size of standardized coefficients (Betas). In Table 1 the Betas for wealth are higher than for income in both equations. In the case of life satisfaction, it appears that the wealth variable is just slightly more 'important' than the income variable (Beta $=0.07$ compared with 0.05 ), whereas for financial satisfaction the difference is much greater $(0.22$ compared with 0.13$)$. On the other hand, the combined effect of all 'objective' variables, including those measuring economic circumstances, is such as to account for just 8.1 per cent of the variance in life satisfaction and a more solid 17.5 per cent of the variance in the domain-specific measure of financial satisfaction.

The results were very similar when the equations were estimated separately for men and women. Also, only minor differences were found when additional control variables were introduced. These included measures of occupational status and home ownership.

In order to get a better handle on the key empirical issue, we now estimate differences in well-being that would result from being at sharply different points in the distributions of

$7 \quad$ The measure of financial ill-being is actually a count of the number of different types of financially stressful events experienced in the last year. A more appropriate estimator for this type of data is provided by the Poisson regression model. Again, however, estimates from this model were qualitatively very similar to the least squares regression estimates. 
both wealth and income. Imagine two people, one at the $25^{\text {th }}$ percentile on both measures and one at the $75^{\text {th }}$ percentile. These people are quite far apart, but panel studies show that moving this far up or down the ladder is not uncommon over, say, a decade (Goodin et al. 1999). Straightforward arithmetic, based on the evidence in Table 1, shows that a person who moved up the 'economic ladder' by these 50 steps would gain 2.0 percentiles on the life satisfaction scale and 8.7 percentiles on the financial satisfaction scale. Conversely someone who dropped 50 rungs on the ladder would drop by these percentiles. The gains and losses would be about equally due to wealth and disposable income. The 2.0 percentile gain in life satisfaction would be 1.1 percentiles due to wealth and 0.9 due to income. The 8.7 percentiles gain in financial satisfaction breaks down into 3.4 percentiles due to income and 5.3 due to wealth.

Continuing with the issue of whether the bottle is half empty or half full, similar calculations show that moving 50 percentiles up the economic ladder brings less than half the gain in life satisfaction that comes from getting married or partnered (which brings a gain of 5.5 percentiles), but is better than getting married as a means of increasing financial satisfaction, although getting married is not bad for that either (gain $=3.3$ percentiles). Another comparison can be made with unemployment. Getting a job increases life satisfaction by 4.3 percentiles and increases financial satisfaction by 15.2 percentiles; both these gains are clearly larger than the effects of moving up the economic ladder. On the other side of the ledger, moving up or down the economic ladder makes a far bigger difference than is found between women and men (women are a little happier, as noted above), between older and younger people (older people are a little happier), or between homeowners and tenants (homeowners are happier). 
Overall, the results presented here suggest that wealth is more important for wellbeing than income. Moreover, we expect our results to understate the relative importance of wealth given it is almost certainly not as well measured, which usually has the effect of attenuating statistical relationships. Finally, it might be worth asking which components of wealth make most difference to well-being. More detailed analyses showed that, in Australia, housing and superannuation assets are the two significant components. By themselves other specific types of assets and debts are not significant at the 5 per cent level. However, the most highly aggregated measure - the measure of net worth used in Table 1 - has the strongest relationship with all subjective outcomes.

\section{(ii) Ill-being}

Australians averaged 73.5 on the $0-100$ SF-36 standardized mental health scale. This not a high score by international standards and indicates fairly high levels of anxiety and stress. Australia, like Sweden and the United States, is in fact a country that has high average ratings on well-being and fairly high ratings on ill-being. Australian women have slightly lower mental health score men and feel a slightly greater sense of financial stress. The mental health result may seem odd in view of the fact that women score higher on life satisfaction, but is in fact in line with previous findings (e.g., Headey and Wearing 1992; Henderson et al. 1981). The usual result of gender comparisons is that women score higher on both positive emotions (positive affect) and negative emotions (negative affect). They are both more up and more down than men.

The Pearson correlations of wealth and income with mental health were, respectively, 0.16 and 0.10 . This is the same pattern as the correlations with life satisfaction and again suggests that wealth matters to subjective outcomes at least as much as income. The 
correlations with the domain specific measure of 'financial stress' were, as expected, higher at -0.43 and -0.26 .

Table 2 now provides the evidence for assessing the net effects of wealth and income on ill-being. These results differ from those for well-being in two important respects. First, only wealth appears to matter for mental health. The relationship with income was not statistically significant even at the $10 \%$ level. This is not altogether surprising, and suggests that mental health outcomes may be associated more with variations in economic circumstances in the longer-term rather than the more short-term effects associated with income variability.

Let us now use the results in Table 2 to estimate the effects of changes in economic circumstances on ill-being. Moving from the $25^{\text {th }}$ to the $75^{\text {th }}$ percentiles of both wealth and income would (inferentially) improve one's mental health by 1.2 percentiles and reduce one's perceived financial stress by 6.9 percentiles. The gain in mental health would be wholly due to wealth, and the decline in financial stress would be mainly due to this variable (5.4 percentiles compared to 1.5$)$.

Finally, we may note that improvements in economic circumstances of the magnitude envisaged would appear likely to have less impact in improving mental health, but more impact in relieving financial stress than some other major life changes, including getting married and getting a job after a period of unemployment.

\section{Discussion}

This paper has shown that objective economic circumstances matter a good deal more to well-being and ill-being or, one can loosely say, to happiness than suggested by previous 
empirical studies. Wealth (net worth) appears to matter at least as much as income, so its inclusion changes our picture of the importance of economics to well-being. Wealth is probably important because it provides economic security, which many people value highly. Future work may well show that other measures of living standards, including consumption, have significant additional effects. This is not to claim that previous research was wrong in emphasising that personality and personal relationships are more important to well-being and ill-being than material factors, but the unimportance of material circumstances has been exaggerated, largely as a consequence of omitting all variables bar income. In many cases, too, researchers have relied on measures of pre-tax, pre-transfer income - rather than equivalised disposable income - and so have omitted the main effects of government policy in redistributing income and potentially redistributing well-being and ill-being.

Arguably, our results have implications both for the psychology literature on happiness and for welfare economics. The implications for psychology are obvious and just involve a modified understanding of what matters to well-being and ill-being. The implications for economics are subtler. If the 'revealed preferences' approach survives the challenges it currently faces, then research on happiness will presumably remain on the fringe of economics. If, on the other hand, it comes to be accepted by increasing numbers of economists that gains in utility cannot be validly inferred from gains in consumption and leisure, then issues will arise about the direct measurement of utility/happiness. It will then be comforting to know that household living standards - and therefore, by inference, national economic growth - matter quite substantially to utility/happiness. 


\section{REFERENCES}

Andrews, F.M. and Withey, S.B. (1976), Social Indicators of Well-being: Americans' Perceptions of Quality of Life, Plenum Press, New York.

Argyle, M. (1987), The Psychology of Happiness, Routledge, London.

Blanchflower, D.G. and Oswald, A.J. (2004), 'Well-being Over Time in Britain and the USA', Journal of Public Economics, 88, 1359-1386.

Bradburn, N.M. (1969), The Structure of Psychological Well-Being, Aldine, Chicago.

Buhmann, B., Rainwater, L. Schmaus, G. and Smeeding, T.N. (1988), 'Equivalence Scales, Well-being, Inequality and Poverty: Sensitivity Estimates Across Ten Countries, Using the Luxembourg Income Study (LIS) Database', The Review of Income and Wealth, 34, $115-42$.

Campbell, A., Converse, P.E. and Rodgers, W.L. (1976), The Quality of American Life: Perceptions, Evaluations, and Satisfactions, Russell Sage Foundation, New York.

Clark, A. (2003), 'Unemployment as a Social Norm: Psychological Evidence from Panel Data', Journal of Labor Economics, 21, 323-351.

Creedy, J. (1986), Edgeworth and the Development of Neoclassical Economics, Basil Blackwell, Oxford.

Diener, E. (1984), ‘Subjective Well-being’, Psychological Bulletin, 95, 542-575.

Diener, E., Suh, E.M., Lucas, R.E. and Smith, H.L. (1999), 'Subjective Well-being: Three Decades of Progress', Psychological Bulletin, 125, 276-302. 
Diener, E. and Biswas-Diener, R. (2002), 'Will Money Increase Subjective Well-being? A Literature Review and Guide to Needed Research', Social Indicators Research, 57, 119169.

Duesenberry, J.S. (1949), Income, Saving and the Theory of Consumer Behavior, Harvard University Press, Cambridge.

Frank, R.H. (1985), 'The Demand for Unobservable and Other Nonpositional Goods', American Economic Review, 75, 101-16.

Frey, B.S. and Stutzer, A. (2000), 'Happiness, Economy and Institutions', The Economic Journal, 110, 918-938.

Frey, B.S. and Stutzer, A. (2002), 'What Can Economists Learn From Happiness Research?' Journal of Economic Literature, 40, 402-435.

Frijters, P., Haisken-DeNew, J. and Shields, M.A. (forthcoming), 'The Value of Reunification in Germany: An Analysis of Changes in Life Satisfaction', Journal of Human Resources.

Easterlin, R.A. (1974), 'Does Economic Growth Improve the Human Lot? Some Empirical Evidence', in: P.A. David and M.W. Reder (eds), Nations and Households in Economic Growth: Essays in Honor of Moses Abramowitz, Academic Press, New York: 89-125.

Goodin, R.E., Headey, B.W., Muffels, R. and Dirven, H-J. (1999), The Real Worlds of Welfare Capitalism, Cambridge University Press, Cambridge.

Headey, B.W., Kelley, J. and Wearing, A.J. (1993), 'Dimensions of Mental Health: Life Satisfaction, Positive Affect, Anxiety and Depression', Social Indicators Research, 29, 63-83. 
Headey, B.W., Marks, G. and Wooden, M. (forthcoming), 'The Structure and Distribution of Household Wealth in Australia', Melbourne Institute Working Paper Series, Melbourne Institute of Applied Economic and Social Research, University of Melbourne.

Headey, B.W. and Wearing, A.J. (1992), Understanding Happiness, Longman Cheshire, Melbourne.

Henderson, S., Byrne, D.G. and Duncan-Jones, P. (1981), Neurosis and the Social Environment, Academic Press, New York.

Hollaender, H. (2001), 'On the Validity of Utility Statements: Standard Theory Versus Duesenberry's', Journal of Economic Behavior and Organization, 45, 227-49.

Juster, F.T., Smith, J.P. and Stafford, F. (1999), 'The Measurement and Structure of Household Wealth', Labour Economics, 6, 253-276.

Kahnemann D., Diener, E. and Schwarz, N. (1999), Well-Being: The Foundations of Hedonic Psychology, Russell Sage Foundation, New York.

Mullis, R.J. (1992), 'Measures of Economic Well-being as Predictors of Psychological Wellbeing', Social Indicators Research, 26, 119-135.

Oswald, A.J. (1997), 'Happiness and Economic Performance', The Economic Journal, 107, 1815-1831.

Samuelson, P.A. (1938), 'A Note on the Pure Theory of Consumer's Behavior', Economica, $5,61-71$.

Shields, M. and Wooden, M. (2002), 'Investigating the Role of Neighbourhood Characteristics in Determining Life Satisfaction', Melbourne Institute Working Paper 
Series no. 24/03, Melbourne Institute of Applied Economic and Social Research, University of Melbourne.

Watson, N. and Wooden, M. (2002), 'The Household, Income and Labour Dynamics in Australia (HILDA) Survey: Wave 1 Survey Methodology', HILDA Project Technical Paper Series no. 1/02, May, Melbourne Institute of Applied Economic and Social Research, University of Melbourne. 
TABLE 1

Impact of Wealth and Income on Well-Being:

OLS Regressions (robust standard errors in parentheses)

\begin{tabular}{|c|c|c|}
\hline Explanatory variables & Life satisfaction $^{\mathrm{a}}$ & Financial satisfaction $^{a}$ \\
\hline Equivalised income (/1000) & $\begin{array}{l}.04[\beta=.05]^{* * *} \\
(.01)\end{array}$ & $\begin{array}{l}.14[\boldsymbol{\beta}=.13]^{* * *} \\
(.01)\end{array}$ \\
\hline Log net worth & $\begin{array}{l}.57[\beta=.07] * * * \\
(.14)\end{array}$ & $\begin{array}{l}2.96[\beta=.22] * * * * \\
(.21)\end{array}$ \\
\hline $\operatorname{Sex}(f=1, m=0)$ & $\begin{array}{l}.93 * * \\
(0.35)\end{array}$ & $\begin{array}{l}.47 \\
(.51)\end{array}$ \\
\hline Age & $\begin{array}{l}-1.23 * * * \\
(0.17)\end{array}$ & $\begin{array}{l}-1.62 * * * \\
(.25)\end{array}$ \\
\hline Age squared (/10) & $\begin{array}{l}.02 * * * \\
(.002)\end{array}$ & $\begin{array}{l}.02 * * * \\
(.003)\end{array}$ \\
\hline Partnered & $\begin{array}{l}5.52 * * * \\
(.45)\end{array}$ & $\begin{array}{l}3.34 * * * \\
(.63)\end{array}$ \\
\hline Educational attainment & & \\
\hline Tertiary degree & $\begin{array}{l}-.10 \\
(.62)\end{array}$ & $\begin{array}{l}3.24 * * * \\
(.90)\end{array}$ \\
\hline Trade qualification & $\begin{array}{l}1.18^{*} \\
(.60)\end{array}$ & $\begin{array}{l}.36 \\
(.86)\end{array}$ \\
\hline Less than 12 years schooling & $\begin{array}{l}2.78 * * * \\
(.66)\end{array}$ & $\begin{array}{l}1.07 \\
(.95)\end{array}$ \\
\hline Employment status & & \\
\hline Employed & $\begin{array}{l}-.39 \\
(.53)\end{array}$ & $\begin{array}{l}3.85 * * * \\
(.77)\end{array}$ \\
\hline Unemployed & $\begin{array}{l}-3.90^{* *} \\
(1.29)\end{array}$ & $\begin{array}{l}-11.33^{* * *} \\
(1.71)\end{array}$ \\
\hline Disability status & & \\
\hline Severe disability & $\begin{array}{l}-15.38 * * * \\
(3.42)\end{array}$ & $\begin{array}{c}-10.94 * * \\
(3.55)\end{array}$ \\
\hline Moderate disability & $\begin{array}{l}-6.15 * * * \\
(0.68)\end{array}$ & $\begin{array}{c}-6.59 * * * \\
(.89)\end{array}$ \\
\hline Mild disability & $\begin{array}{l}-2.61 * * * \\
(0.81)\end{array}$ & $\begin{array}{l}-3.57^{* *} \\
(1.14)\end{array}$ \\
\hline Constant & $\begin{array}{l}88.60 * * * \\
(24.73)\end{array}$ & $\begin{array}{l}45.14^{* * *} \\
(8.76)\end{array}$ \\
\hline R squared (adjusted) & 0.081 & 0.175 \\
\hline Model F & $37.02 * * *$ & $94.29 * * *$ \\
\hline Breusch-Pagan & $430.76^{* * *}$ & $261.03 * * *$ \\
\hline Ramsey RESET & 2.10 & $38.69 * * *$ \\
\hline $\mathrm{N}$ & 7934 & 7931 \\
\hline
\end{tabular}

Notes: a. Metric coefficients are shown for all explanatory variables. For income and wealth, standardized coefficients $[\beta \mathrm{s}]$ are also given to assist comparisons of their relative importance.

*** significant at .001 level; ** significant at .01; * significant at $.05 ; \mathrm{ns}=$ not significant.

The reference variable for education was 'completed year 12' and the reference variable for employment status was 'not in the labour force'. For disability status the reference is 'no disability'. 
TABLE 2

Impact of Wealth and Income on Ill-Being:

OLS Regressions (robust standard errors in parentheses)

\begin{tabular}{|c|c|c|}
\hline Explanatory variables & Mental health ${ }^{\mathrm{a}}$ & Financial stress $^{\mathrm{a}}$ \\
\hline Equivalised income (/1000) & $\begin{array}{l}.01[\beta=.01] \\
(.01)\end{array}$ & $\begin{array}{l}-.06[\boldsymbol{\beta}=-.08]^{* * *} \\
(.01)\end{array}$ \\
\hline Log net worth & $\begin{array}{l}.61[\beta=.06]^{* * *} \\
(.15)\end{array}$ & $\begin{array}{l}-2.99[\beta=-.31] * * * \\
(.18)\end{array}$ \\
\hline $\operatorname{Sex}(f=1, m=0)$ & $\begin{array}{l}-1.87 * * * \\
(0.41)\end{array}$ & $\begin{array}{l}.31 \\
(.36)\end{array}$ \\
\hline Age & $\begin{array}{l}-.91 * * * \\
(0.20)\end{array}$ & $\begin{array}{l}.69^{* * *} \\
(.18)\end{array}$ \\
\hline Age squared (/10) & $\begin{array}{l}.01 * * * \\
(.002)\end{array}$ & $\begin{array}{l}-.01 * * * \\
(.002)\end{array}$ \\
\hline Partnered & $\begin{array}{l}2.74 * * * \\
(.51)\end{array}$ & $\begin{array}{c}-3.08 * * * \\
(.50)\end{array}$ \\
\hline Educational attainment & & \\
\hline Tertiary degree & $\begin{array}{l}.05 \\
(.73)\end{array}$ & $\begin{array}{r}-1.30^{*} \\
(.64)\end{array}$ \\
\hline Trade qualification & $\begin{array}{l}.33 \\
(.70)\end{array}$ & $\begin{array}{l}.89 \\
(.64)\end{array}$ \\
\hline Less than 12 years schooling & $\begin{array}{l}-.35 \\
(.75)\end{array}$ & $\begin{array}{l}1.34 \\
(.69)\end{array}$ \\
\hline Employment status & & \\
\hline Employed & $\begin{array}{l}3.46^{* * *} \\
(.60)\end{array}$ & $\begin{array}{l}-3.08 * * * \\
(.58)\end{array}$ \\
\hline Unemployed & $\begin{array}{l}-1.08 \\
(1.35)\end{array}$ & $\begin{array}{l}6.37 * * * \\
(1.56)\end{array}$ \\
\hline Disability status & & \\
\hline Severe disability & $\begin{array}{l}-18.35 * * * \\
(3.11)\end{array}$ & $\begin{array}{l}1.58 \\
(2.52)\end{array}$ \\
\hline Moderate disability & $\begin{array}{l}-12.23 * * * \\
(.77)\end{array}$ & $\begin{array}{l}5.41 * * * \\
(.75)\end{array}$ \\
\hline Mild disability & $\begin{array}{l}-3.79 * * * \\
(.91)\end{array}$ & $\begin{array}{c}.43 \\
(.75)\end{array}$ \\
\hline Constant & $\begin{array}{l}79.85^{* * *} \\
(19.09)\end{array}$ & $\begin{array}{l}40.67 * * * \\
(10.54)\end{array}$ \\
\hline R squared (adjusted) & 0.109 & 0.236 \\
\hline Model F & $44.70 * * *$ & $93.56^{* * *}$ \\
\hline Breusch-Pagan & $260.54 * * *$ & $1781.21 * * *$ \\
\hline Ramsey RESET & $5.11 * *$ & $62.27 * * *$ \\
\hline $\mathrm{N}$ & 7067 & 7027 \\
\hline
\end{tabular}

Notes: a. Metric coefficients are shown for all explanatory variables. For income and wealth, standardized coefficients $[\beta \mathrm{s}]$ are also given to assist comparisons of their relative importance.

*** significant at .001 level; ** significant at .01; * significant at $.05 ; \mathrm{ns}=$ not significant.

The reference variable for education was 'completed year 12' and the reference variable for employment status was 'not in the labour force'. For disability status the reference is 'no disability'. 